\title{
Importance levels of skills and traits for successful long-term police careers: comparisons of mid west police chief and commissioners of the Caribbean Islands responses
}

\begin{abstract}
The kinds of personal skills and traits that police chiefs in five Midwestern states of Illinois, Iowa, Indiana, Ohio, Nebraska, and the Caribbean Islands desire in recruits are illustrated and compared in this article. Two separate areas are considered, preparing for the training and long-term career success. The desired traits and skills chiefs and commissioners believe necessary to determine recruits' chances for success as police officers and success through basic, in service, and specialized training. Having these skills and traits are instrumental in determining success throughout the selection assessments. The intent of the surveys is to define the importance levels of skills and traits (attributes) police chiefs believe increase success rates of recruits including career enrichment for advancement. The police chiefs in the Midwestern and Caribbean commissioners believe these skills and traits (attributes) increase the likelihood of a successful and a long police career. This article constitutes one half of 12 replicated surveys about police chiefs' preferred recruit skills and traits.
\end{abstract}

Volume 8 Issue 2 - 2020

\author{
Richard H Martin \\ Department of Leadership Studies, Mercer University, USA
}

Correspondence: Richard H Martin, Professor of Criminal Justice, Department of Leadership Studies, Mercer University, USA, Tel 419-348-420I, 25230, Email drdickmartin@gmail.com

Received: March 30, 2020 | Published: April 24, 2020

Keywords: police, agencies, polygraph, selection process

\section{Introduction}

Policing is very demanding. Some say the occupation is a profession. But based on the elements required for a true profession, policing is still lacking an element or two (such as a universal college degree requirement). However, some agencies may have all of the elements. It is important to note that officers may be professional in their duties, even though their agency may be lacking all of the elements of a true profession. Problem solving in the community requires officers to be analytical and creative. ${ }^{1}$ Police performance is enhanced through quality selection of excellent recruits. This is accomplished through superior selection procedures and meaningful training. Finding the recruits with the skills and traits (attributes) that make a good career officer is imperative. There are some attributes in recruits that are subjectively more important than others. The choices of selected importance levels by the chiefs responding in the surveys provide important feedback about the types of attributes they believe essential for new recruits to have successful careers. It is crucial to find recruits who can deliver the service necessary in community and problem-oriented policing (C\&POP). These officers are more likely to become career officers since successful job performance can increase morale. These attributes are not always identified during the selection process, but they should be. Selection should be a process of screening in those recruits with the attributes conducive to contemporary policing and C\&POP. Too many agencies continue to screen out applicants rather than screen in recruits with the necessary attributes. ${ }^{2,3}$ The steps in the selection process are like hurdles that the recruits try to get over. If they fail to overcome the hurdle, they are screened out, eliminated from the process, even when they have traits and skills favorable to good policing careers and subsequent training. Tests used for screening out are not as reliable for the selection process as those that attempt to screen in applicants. Selecting candidates that lack the skills and traits to be successful in this challenging job is harmful to the public and the recruit. Unfortunately, human resources and police agencies are not able to define a method to select applicants that will become successful career officers. ${ }^{1}$ Intelligence is one attribute that is important in policing. Research has indicated a correlation of low intelligence scores with negative police performance, although high intelligence scores do not correlate with positive police performance. ${ }^{1}$ A common test used in selection is the Minnesota Multi phasic Personality Inventory $\left(\mathrm{MMPI}_{2}\right)$ screens out applicants with mental irregularities, but the MMPI ${ }_{2}$ and other psychological examinations are not able to determine the best career officers. Most examinations for selection are those proclaimed by vendors that have a focus on screening out applicants with objectionable physiognomies. ${ }^{1}$ Before agencies determine the specific examinations to be used for selection, they should determine whether the exam includes the chief's level of importance of desired skills and traits. Do they screen out or screen in applicants? Assessments should address the desired attributes based on the agencies need for recruit success in basic and in service training and long-term career in policing.

This article represents results of 12 separate surveys (11 replicated) of police chiefs in several Midwest and southern states, and the Caribbean regarding attributes believe lead to successful career performance. Tables allow comparisons of what they believe are important attributes. The term attributes, characteristics, traits, and skills are used interchangeably throughout the article and for the purpose of this report, mean the same. The survey instrument used selected attributes determined from research by Jefferey Gwynne in 1994. The attributes developed from his research enhance the value of recruit preparation and policing procedures. ${ }^{2,3}$ The survey instrument asked the police chiefs about their mind sets on the levels of importance of particular skills and traits needed for success in basic and in service training, and a successful career in policing. The instrument identified some important skills and traits to look for during the selection 
process. Questions to be considered include: (1) What methods do agencies use to select recruits with the most desired characteristics? (2) Is selection a major component along with appropriate training in predicting officer success? (3) What characteristics lead to officer success? The results will assist agencies in determining selection criteria for successful training and careers.

\section{Midwest and southeast surveys}

The overall project has involved several surveys administered to southern and Midwestern states police chiefs and Caribbean commissioners. The first survey involved Alabama police chiefs, followed by surveys of police chiefs in Georgia, South Carolina, North Carolina, Florida, and Texas. The Midwest states surveyed were Illinois, Iowa, Nebraska, Indiana, and Ohio. The Caribbean Island Commissioners are included with the Midwest states. It makes sense to compare the similarities of Midwestern state surveys, and the southern state surveys separately, so the southern state surveys are not included in this comparison.

A limited number of companies offer assessments and strategies used by police agencies for selection of employees. ${ }^{4}$ Unfortunately, the existing assessments have not changed much over the years, possibly because the assessments are too costly to make changes, maybe because of agencies' resistance to change, maybe agencies rely on assessment vendors and consultant psychologists' recommendations and what they proclaim the tests will do for a competitive price. But not one consultant or vendor will say their assessments choose career officers, but they should. A cynic might say that the more turnover an agency has the more money the vendors will make over the years. It is hoped that the results of the 12 surveys will lead to the development of candidate selection assessment methods and subsequent recruit training that emboldens police officer success. This article shows similarities in the chiefs' selections by comparing regional choices among the chiefs. The attributes desired by the police chiefs in these three regions (mid western and southern states, and Caribbean Islands) sought in the recruit selection process are believed to enhance training and operational effectiveness.

\section{Skills and traits}

The selected skills and traits are believed to be essential for successful performance and growth of entry-level police candidates. What is the difference between a skill and a trait? Police are a primary core of government in communities. Within that context, they are the most visible entity of the government and subject to almost constant scrutiny and potential criticism while interacting daily with the community. As such, police administrators must select and train officers who have the mental and physical abilities to meet the constant changing needs of communities. Law enforcement officers (LEOs) must have the emotional temperament to lead ethical lifestyles.

Unethical and corrupt actions lead to litigation and lack of trust in the community. Such an atmosphere works against the stability of an agency and creates a negative persona of policing: "Entrylevel assessment and training is therefore one of the most important processes toward developing a strong, stable, and responsible police force". ${ }^{2}$

\section{Purpose of study}

The purpose of these studies was to gain an understanding of what police chiefs desired in a candidate's skill and trait (also known as attributes)profile, and to determine the importance of a recruit's general reasoning ability for basic training, probationary, and long-term work assignments. Several surveys were administered to 12 entities in an attempt to determine the attributes desired by police chiefs in those jurisdictions. The questionnaire surreptitiously evaluated the selection process as well as training satisfaction. Gaining an understanding of the levels of importance of traits and skills police chiefs' thought were important for maintaining successful earning and practice in police procedures. These skills and traits are essential in basic training, field training and the probationary period, in service training, and specialized training. ${ }^{5}$

The study also attempted to understand the intellectual skills and attributes that police chiefs believe are necessary for success in training and policing. The researcher also wanted to know the level of importance the chiefs assigned for each attribute desired for police officer success in training and a long-term career in policing. ${ }^{2}$ The data collected about the attribute importance relates to both selection and training in the various states. However, the literature review is mostly about selection, and not so much on training. The survey measured the police chiefs' opinions about importance levels of desired skills and traits (attributes), and the cognitive abilities of recently certified recruits. By choosing the level of importance of specified attributes that should be sought in applicants during the selection process, the chiefs believed the attributes most likely will lead to career success.

\section{Literature review}

The selection process is where potential performance is evaluated. When judicious selection takes place, LEOs enter their assigned agencies with characteristics to connect with their community, psychologically, physically, and emotionally. Intelligent selection and employment prerequisites require thorough background investigation. ${ }^{6}$ Agencies make a major mistake when they try to save expense on conducting a personal history of applicants. The importance of a thorough background investigation cannot be over emphasized. It can be an accurate predictor of a successful police career. Results of an applicant's personal history can reveal skills, uncover lifestyles, and measure incentive, as well as highlighting past performance and behavior issues. Background investigations can help predict future positive and negative attitude and behavior issues. Past behavior under similar situations is the best predictor of future behavior. The background investigation should delve deeply into education, behavior, honesty, motivation, and self-esteem. ${ }^{7}$ Such a procedure bolsters support from existing LEOs by hiring recruits with the proven traits for the job. As part of the selection process, it is also necessary to select candidates with the abilities to succeed in training. There are three types of common training for police: (1) basic training, (2) in service training, and (3) specialized or career development training. ${ }^{8,9}$

Recruiting for selection is based on departmental needs. Selection criteria includes verifying the accuracy of candidate information in the application. There are several instruments of assessment used to evaluate candidate suitability. Assessment tools for selection should provide an evaluation useful for both selection of recruits and training of officers similar to utilizing Scholastic Aptitude Test (SAT) scores as a predictor of success in college. It was determined after a 10-year study conducted by one of the authors that recruit levels of success greatly increased, in the academy and organizationally when they were profiled into areas designed to evaluate each recruit against proven norms preceding any employment or educational processing. ${ }^{2}$ 
Determining which candidates will have a successful career in policing is critical in selection. Validated criteria used in assessment tools provides agencies the wherewithal to find recruits with the best attributes for success in basic training and field training, an extension of basic training, and c a r e e $r$ policing. Success in these are helps corroborate that agencies have used the right methods to make the right decision when hiring recruits. The hiring process is further refined toward officer effectiveness and stability with in service and specialized training. Higher police officer success rates are more likely when validated instruments are used that recognize the attributes that impact officer success rates.

Research toward improving selection methods and techniques must continue in order to select and develop recruits with the potential to perform productively land ethically. Methods of assessment in selection have not changed much in several decades, while the type of service provided by police frequently change and are becoming increasingly more complex. Deciding on the instruments to use in selection is critical. How does an agency do this? Answers to the following questions may help identify the traits desired in entry-level police candidates to be successful. For example, what is the depth of the inquiry of instruments used? Are the tools of assessment used to manage applicant employment lists or are they directed toward a specific need such as the ability to complete basic training? Is the ability to make street-level decisions based on judgment measured? What is the success rate of training academy recruits based on selection-based data? Are probationary period problems encountered, and can they be tied to the lack of sound selection tools?

The right attributes are necessary for police to provide the necessary services in community and problem-oriented policing. Today's police are required to be proactive and creative when solving citizen problems. ${ }^{1}$ The selection process should identify the desired attributes. Progressive agencies screen in, but many agencies still attempt to screen out based on undesirable attributes rather than identifying recruits with attributes that are positive for the agency. ${ }^{10,11}$ Without the proper attributes, the recruit is at a disadvantage. The attributes in this survey are what the police chiefs believe will lead to successful police careers. Because of enhanced visibility through social media, it is imperative to select recruits with the potential to successfully perform their duties.

\section{Positive selection}

The items in the survey were designed to determine knowledge and reasoning ability for basic training and later probationary assignments to gain a better understanding of what police chiefs preferred in an applicant's aptitude profile. Questions also furtively evaluated satisfaction of the selection and training processes. ${ }^{2}$

There is more resistance to police today when a violator is detained. Assaults, deadly attacks, even assassinations are more common. Citizen perception of the media by many is that the media are siding with the bad guys. Good judgment in decisionmaking when interacting with citizens while providing services and maintaining order is required. Candidates should have the mental and physical abilities to perform in a changing society and the integrity to resist corruption and excessive force. Selection is the first place where future performance is evaluated. As such, selection and training are important processes in developing an effective and respected police force. ${ }^{3}$ Evaluation of an officer psychologically, physically and emotionally for fitness of future performance takes place during selection. Intelligent selection is the first step toward intelligent policing. A thoroughly focused background investigation has been found to be one of the most accurate predictors of career success. Investigation of an applicant's background must be thorough, since one of the best predictors of future behavior is an applicant's historical behavior (p. 95). Analysis of the candidate's background should examine deeply into education, contacts, experiences, behavior, level of honesty, motivation, and self-esteem. ${ }^{7}$ An all-inclusive review of past behavior can be used to measure skills, uncover lifestyles, and measure incentive, while helping to predict future issues of attitude and behavior. When selection is done carefully, officers enter their agencies with the psychological, physical, and emotional characteristics to connect with citizens in a diverse community. This approach gains the support from existing personnel by hiring recruits with the attributes and incentives to perform appropriately. ${ }^{7}$

Selection assessment is based on agency needs and includes verification of the accuracy of the application information provided by the candidate. Several instruments are used to assess applicant suitability for the job. It is important to establish a reliable police training program to determine basic suitability of individuals who participate in the training process. The selection process should meet the organization's needs. Appropriate training allows participants at all levels of the organization opportunities to reach higher levels of understanding and individual goal attainment. ${ }^{3}$ Selection Assessment tools selected should provide a comprehensive evaluation of candidates before selection. Jeff Gwynne's study found that candidate success increased considerably during training and careers when candidates were profiled into separated areas intended to evaluate each candidate against benchmarks or standards before any training or selection processing. ${ }^{3}$

\section{Selection}

Assessment tools are supposed to choose candidates with the potential to perform policing effectively and ethically. Assessment methods toidentify new police candidates have not changed much in the past 30 years, while the service provided by police agencies frequently change with increased complexity. How does an agency decide in the selection process? What is the depth of the inquiry of instruments used? Does the agency choose one of the four most popular instruments or one of the other somewhat popular instruments, e.g., MMPI, IPI, PST, CPI ${ }^{6}$ Does the agency follow the recommendation of the consulting psychologist? Are the tools of assessment used to manage applicant employment lists or are they directed toward a specific need such as the ability to complete basic training? Is the ability to make streetlevel decisions based on judgment measured? What is the success rate of training academy recruits based on selection-based data? Are probationary period problems encountered, and can they be tied to the lack of sound selection tools?

\section{Literature review}

Selection assessment is the basis used to verify the accuracy of the applicant's application information and fitness for duty. A series of selection instruments are used in the process to assess suitability for the job. Establishing reliable and credible police training curricula is an important factor to determine suitability of applicants to meet organizational needs, while allowing candidates to excel academically and achieve their goals. ${ }^{3}$

Consultants and psychologists who market pre-employment 
screening methods should recognize the need to continually strive on improving their products for better selection methods and techniques. The selection process has been somewhat stagnant for several years because of the research involved in selecting the methods based on agency needs. The criteria for selection should come from police chiefs, not those in other industries or human resources. Police services change frequently with the changes of their communities. Policing is more complex, as such agency needs are reflected in the community needs. How does an agency make the right decision in the selection process? Answers to the following questions may help to determine procedures to identify the potential for successful performance in entry-level police candidates. What is the depth of the inquiry of instruments used? Are cognitive tools utilized to simply manage candidate numbers (create employment lists) or are they purposed toward a specific need such as an applicant's ability to successfully complete academy training? Do selection criteria include measuring the ability to make street- level decisions? What is the success rate of recruits while in the basic training academy based on selectionbased information? What special problems encountered during the probationary period can be tied to the need for better selection tools? Police recruitment will be even more challenging with the Gen Xers and Baby Boomers retiring. Well-defined selection strategies can develop a large pool of respectable candidates with skills and traits that can shape an agency's character and future. ${ }^{12}$ Cordner $^{13}$ stated that selecting recruits with the desired attributes means that "CEOs and HR officials might need to communicate and coordinate more closely". ${ }^{2}$

\section{Selection attributes}

To select the recruits with the desired attributes, police chiefs, in collaboration with human resources, need to define the attributes that lead to success in training and productive careers in policing for their agencies. According to Cordner ${ }^{13}$ outcomes of recruitment in agencies with 24 or less officers and larger agencies with more than a 1,000, found that 45 percent of police chiefs were not satisfied that recruits had the skills and traits the chiefs preferred (p. 14).However, human resource departments were more satisfied than the chiefs, indicating a lack of understanding about the type of recruit the police chiefs wanted. Apparently, something was missing in the selection process? Moreover, large agencies were more satisfied than small ones. Seventyeight percent of the chiefs said they wanted to attract candidates with college degrees; 63 percent of large and small agencies wanted recruits already certified with pre service training; and 66 percent of those that preferred pre service basic training were from small agencies; whereas, only 13 percent of larger agencies wanted pre-trained recruits. Ninety percent of the police chiefs desired good writing and speaking skills as well as critical thinking and problem-solving skills. They recommended that colleges put more emphasis on these skills. When asked about incorporating basic training in their undergraduate curricula, 51percent indicated they were in favor of integrating the two, something that nurses and teachers adopted years ago as an education and practice model. Cordner ${ }^{13}$ argued that police chiefs needed to identify specific attributes and convey these preferences to their human resources departments. ${ }^{2}$ Agencies should determine the methods of selection based on criteria their current agency needs, not previous benchmarks. "Selection and training should meet the needs of the organization and allow recruits to increase personal knowledge and goal achievement". ${ }^{3}$ Selection includes an assessment of information provided by applicants. An applicant's job suitability is decided with various selection assessments. When training programs are reliable and relevant, they can identify basic requirements for participants in the training process. It was proposed by Gwynne after 10 years of extensive research that success in basic training and policing was greatly improved when applicants were profiled into groups "designed to compare each applicant with established criteria prior to any educational or employment processing".

\section{Standards for selection}

There is consensus among police chiefs and city managers on the need for training on specific topics, but not there is no consensus for important attributes to look for through selection assessment methods. The evaluation of candidates' potential to perform in policing reliably and productively, is extremely important in protecting the interests of the public. ${ }^{11}$ Selection and training processes must adopt effective standards to meet the demands of contemporary policing and expectations of the public.

Scrivener ${ }^{14}$ conducted a study for the Community Policing Consortium of the U.S. Department of Justice to identify community policing recruits and determine their ideal traits. Several attributes which include both traits and skills were identified as important. These attributes include integrity, demeanor (professional attitude), interpersonal communication, and good decision-making and judgment. Agencies involved in the study were King County, Washington; Burlington, Vermont; Hillsborough County, Florida; Detroit; and Sacramento. Current practices of recruiting are based on the adventure side of policing which focuses on reactive instead of proactive policing. In the past, the Law Enforcement Assistance Administration (LEAA) supported hiring officers who were motivated by the spirit of service rather than by adventure (p. 26). Scrivener ${ }^{14}$ stated that reactive policing distances agencies from their communities. Most selection procedures in police agencies support elimination process as indicated by their selection methods. Generally, agencies choose candidates by selecting out as opposed to selecting in. Selecting out has several hurdles in place to find flaws and disqualify candidates based on something negative, resulting in the suspension of their application process. But these agencies may be missing out on qualified community policing recruits.

\section{Applicant screening out or screening in?}

Applicants who fail any part of selection evaluations are removed from the process, even though these applicants may have the attributes suitable to a community-based policing career. There is no attempt "to identify traits and characteristics associated with success". ${ }^{15}$ Selecting in is a method that, according to Scrivener, ${ }^{14}$ "looks at what is right with the candidate, how he or she meets the criteria that the department is seeking, and evaluates his or her potential for effective job performance" (p. 27). When an officer is terminated from a department, it is generally because of inappropriate job performance that may be the result of inappropriate selection that did not identify appropriate attributes needed. ${ }^{2}$ The command and control approach to policing using the screening out philosophy is not conducive to a problem-solving philosophy that requires critical thinking skills. ${ }^{14}$ Police officers today require a higher level of intellect and social skills to interact appropriately with the community. Officers also need critical thinking ability to solve problems, and they must be competent with technology. It is critical during selection to determine an applicant's ability to successfully complete basic training and have the qualities to add value over time to the agency. ${ }^{2}$ Selecting in provides agencies a better chance of finding officers with the desired 
attributes for their city. ${ }^{14}$ Validity of instruments used in the selection process is important.

\section{Selection validity}

The selection components are difficult to validate. True validity cannot be established without comparing selection methods against each other method of selection. Results of the selection, training, and probationary evaluation processes of new personnel are typically compartmentalized and kept separate. ${ }^{2}$ How valid are the processes used for recruit selection? According to Hunter, ${ }^{16}$ the criteria for selection and training curricula are seldom linked to evaluating selection component validity. Criteria and methods used for selection and training need to be validated in a coordinated selection evaluation process. Data on components of recruit preparation, selection, training, and how they complement each other should be evaluated and compared against each component. ${ }^{16}$ Comparing of information can determine what needed improvements. Information sharing can improve preparation, selection, and training of police officers. Assessment of recruits for selection and training of recruits should be in step with agency needs. Selection methods should be based on finding those with the attributes the agency believes necessary for success in policing. The desired attributes (skills and traits) should establish the methods of selection and the basic training curriculum. Since field training is an extension of the selection process, it should be designed to recognize a recruit's deficiencies. Some deficiencies are uncorrectable and should result in dismissal of the recruit. ${ }^{3}$ Furthermore, Coulton ${ }^{17}$ believe that police misconduct results from stress, poor decision making, poor management, and poor supervision, all improper actions that can result in liability for the agency. ${ }^{18}$ Steps in selection and methods of training must address these shortcomings.

\section{Selection steps}

The agency determines the characteristics required for candidates; therefore, the agency's hiring advertisement must list the characteristics required for the position. Here in lies the problem because many agencies are still hiring the same as they did decades ago. The first step in the selection process is attracting a pool of applicants. It begins with the advertisement and ends when the officer completes probation. ${ }^{19}$ The advertisement is the first the first step in the selecting out process. The second step is the written application which includes self-elimination features. It is the industry standard to begin the selection process for agencies, and it has the potential to eliminate some who are interested in applying. For example, if a fee is charged, applicants may opt out paying for the application. Self-elimination also can result when the application is not returned because of the required information. The application is probably the least expensive examination in the selection process, so it is advisable to use the least expensive examinations first and save the most expensive for when the applicant pool is smaller. The exams that fall under the American with Disabilities Act (ADA) should be administered after a conditional offer of employment. ${ }^{19}$

\section{Selection}

After the application is submitted, a physical ability test is administered. Approximately $80 \%$ of agencies use the physical ability test. ${ }^{19}$ A relatively inexpensive inclusion tool, the physical ability test may be conducted early in the process before the interview and either before or after the aptitude test. Next, the applicant is administered an aptitude test usually with a cutoff score of 70 . However, according to Cox et al. ${ }^{19}$ research has shown there is little variation in aptitude for scores that are five to ten points different.

Police officers require strong intellectual and practical skills. They are philosophically and functionally different than their predecessors. They need better critical thinking and problem-solving abilities. They need to adapt cognitively to advancing technology and changing community needs. Appropriate selection methods can identify applicants with the ability to successfully complete training and perform according to department policies. Recruits should add to the value of their agencies. Next, a physical ability test is usually administered, followed by a board interview.

A common tool of selection early in the process, preferably right after the aptitude test, is the formal board interview. It is used to determine a candidate's ability to communicate and sometimes to test for good judgment. Candidates are asked to discuss current news, interest in law enforcement, personal and professional backgrounds, and any investigation discrepancies found in the application or the background check. Next, a background investigation is developed by the department, but sometimes a private investigator is used. The background investigation is a critical step in the process. Investigators typically look at driving and criminal records, but should also look at candidates' neighborhoods and lifestyles. The investigator should conduct an in-depth background check that includes visits to candidates' schools and colleges with interviews of current and former teachers as well as former employers to discuss work ethic, civility, and trustworthiness. Past behavior is a good indicator of future behavior. Credit histories are an important source of verification of information as are past employers, addresses, creditors, credit accounts, and any civil action taken. Two national surveys of police supervisors. ${ }^{4}$ (Harris, n. d.) identified absenteeism, laziness, and slacking (doing just enough to get by) as being problematic.

According to Harris, ${ }^{4}$ candidates and employees may have the psychological, physical, and emotional characteristics to indicate a successful risk for employment, but their past work history indicated a problematic work ethic. ${ }^{3}$ Since the background investigation is more expensive than an oral board interview, it should be one of the last criteria after a conditional offer of employment. A second interview after the background investigation serves to clarify questions arising from the background check. Integrity tests are beginning to be used by some agencies. The U. S. Government Office of Personnel Management (OPM.Gov) believes integrity testing which became popular in the 1980s, also known as honesty testing, will save the agency money by eliminating those who are likely to fail the polygraph and/or the psychological examinations. They are usually included in the aptitude tests, but most test developers are slow to make the changes to the aptitude tests. According to the OPM, "Integrity tests have been shown to be valid predictors of overall job performance as well as many counterproductive behaviors such as absenteeism, illicit drug use, and theft; The use of integrity tests in combination with cognitive ability tests can substantially enhance the prediction of overall job performance". ${ }^{20}$

\section{Psychological examination}

The least expensive examinations used in the early stages will save the agency money while establishing a list of qualified candidates. Administering the psychological examination before a conditional 
offer may violate the ADA. Pre-employment psychological evaluations (PEPE) reduce the risk of negligent hiring in the selection process. ${ }^{6}$ The PEPE can identify the capacity to multi- task; assess resiliency between dealing with graphic injuries and boredom; and assess diversity appreciation, emotional stability, consideration, assertiveness, decisiveness, truthfulness, aggressions, potential for drug abuse. There are several PEPE assessments frequently used. For example, the MMPI, CPI, IPI, and PST. Other assessments used but not as frequently include the16 Personality Factor $\backslash$ Questionnaire, (1a6P), Eysenek Personality Questionnaire, the NEO Five Factor Personality Inventory, and the Hilson Safety/Security Inventory. All of these are self-reporting assessments. Sometimes after the results are reviewed, a psychological interview is arranged. ${ }^{6}$ When comparing candidates' responses with the polygraph examination and the psychological test, a need for an additional interview with the psychologist is determined. The medical examination can be rather expensive, so it should be last before an offer of probationary employment.

\section{Polygraph}

The polygraph is a selection tool that is being used more often by agencies. The polygraph promotes honesty and integrity. It effectively verifies responses to the written application and can corroborate psychological evaluations when used in concert with the psych exam. Agencies serving a million or more population use the polygraph about 81 percent of the time. Approximately 60 percent of police agencies in cities with a population between 50,000 and 100,000 use the polygraph in the selection process..$^{21,22}$ The polygraph examination is inexpensive compared to the costs of a lawsuit. For the best clinical results, polygraph examiners and clinical psychologists should share information about an applicant makes sense for best clarification of responses. Too many agencies keep information separate, when one may explain a negative result of the other. Each examination stage result should be only a small part of the final decision to hire.

Use of Mock Scenes in Selection. One way to evaluate good judgment is using mock scenes. Decicco ${ }^{18}$ suggested using mock crime scenes, simulated traffic stops, and shoot/don't shoot scenarios. However, agencies using these often place the inexperienced applicant at a disadvantage. These kinds of skills are learned in basic and inservice training. Other examinations unrelated to policing may be more appropriate such as those based on situational analysis. ${ }^{18}$ It can serve agencies served just as well to rely on basic and inservice training to determine shooting skills and judgment since most applicants do not have police experience. Even those with a military background may not have these similar types of experiences.

Selection Assessment Centers. Another suggestion by Decicco ${ }^{18}$ to consider is the assessment center (AC), a valuable asset for selection (p. 4). While ACs have normally been used in a promotional venue, there are exceptions. The selecting in AC can provide the agency with a comprehensive profile of the applicant by creating a transcript that includes a number of qualifying selection criteria, such as decisionmaking, critical thinking, aptitude, and social history, and polygraph and psychological evaluations. This can provide less emphasis on test scores and allow flexibility in the decision-making process. The process of selection should utilize profiles and patterns in addition to test scores, thus, allowing an evaluation on the totality of candidate's information rather than on a test-by-test sequence. This provides a synergistic approach toward the decision to hire. ${ }^{18}$ The ACs strength is a measure of validity. A study on validity of ACs found six common dimensions used in the centers: (1) consideration/awareness of others, (2) communication, (3) drive, (4) influencing others, (5) organizing and planning, and (6) problem solving. ${ }^{23}$ Situational assessments using these dimensions can determine, in part, whether the applicant is trainable and also determine critical thinking and analytical skills.

The various dimensions used in ACs were found to have value beyond aptitude tests used in selection of police candidates. ${ }^{24}$ Situational ACs at the entry level should not rely on police-specific responses, but what a reasonable person would do in a similar situation. To decrease liability risks to police agencies, administrators should take great care in selecting recruits. ${ }^{17}$ Skill in decision-making is critical to policing. Agencies should provide frequent training and direction on use of discretion, for example, through situational scenario assessments. Experience is valuable when learning the job, but training is necessary to develop competence to handle the various situations officers may encounter. ${ }^{17}$ Mock scene scenarios serve basic training well by evaluating and helping judgment and shooting skills, and inservice training can maintain proficiency in skills and discretionary decision-making.

Licensing allows states to have a decertifying process in place so that problem officers or officers who may not pass the FTO process cannot be hired by another agency based on a certificate of basic training completion. ${ }^{25}$ States with a licensing process for policing can revoke a license easier than a certificate. For example, if states license officers and have an annual license fee for renewal, states can choose not to renew the license of problem officers based on cause. Licensing can also mandate more hours of annual in service training and continuing education. Required probationary periods can also be part of the licensing requirement (p. 147).

Current Police Operational Functions. Most police activities consist of service and order maintenance functions that occupy officers' time about four times more than law enforcement functions. Do police training programs cover these aspects of police work? Training academy curricula should include these predominant activities, for example, dealing with citizens with mental illness, domestic violence, race relations, discretion, ethical decision making, and citizen relations to name just a few. ${ }^{25}$ Basic training curricula should reflect the actual work environment. In addition, training curricula should be evaluated continually. The in service training can enhance officer performance and provide skills to handle elevated levels of responsibility in various situations. ${ }^{26}$

\section{Design of the study}

The word performance for this project is defined as "the fit between the important job functions in a given police organization and the abilities, skills, and performance-based attributes an individual possesses to successfully perform these job functions". "This study is designed to determine the attributes desired to predict success in law enforcement. ${ }^{3}$ The same instrument was replicated for 12 surveys to allow comparisons of desired attributes in several states and the Caribbean. ${ }^{2,27}$ Answers were sought on how important police chiefs believed these 11 attributes were for recruits' success in their overall training and long-term careers.

\section{Discussion}

In the emails sent by Survey Monkey using the lists provided by the various state police chief associations, the respondents were asked 
to click on a hyperlink at the bottom of the e-mail which connected them to the first question of the survey. Once the first question was answered and submitted, the remaining 10 survey questions became available for response. Survey Monkey (SM) recorded the frequencies and the percentages of the respondents and made them accessible to the researcher. Numerous follow-up requests were sent to those that did not respond. Responses from all of the police chief members in the associations were difficult to obtain, possibly because they are inundated with emails daily, even from their respective associations. The SM collected data included the number of respondents overall and the number of respondents for each of the 11 alternatives. It also calculated the percentages of respondents for each alternative and forwarded the data to the researcher's site. The surveys were open from four to nine months, depending on the rate of return. Several follow up requests were sent by email. The results of the six Midwestern and Caribbean surveys were combined to show item comparisons of the respondents' top two alternatives desired attribute importance. The six southern state surveys are not included in this report.

Survey Items. There are 11 items in the survey instrument concerning police chiefs' desired attributes for police recruits. The survey was designed to allow respondents to select their responses to the 11 items quickly using a 5-alternative Likert Scale: (5) Extremely Important, (4) Very Important, (3) Important, (2) Somewhat Important, and (1) Not Important. The items of the instrument included the following. ${ }^{3}$

1. Memory - The ability to recall the essence of previously studied material.

2. Judgment - The ability to take appropriate action after considering alternative approaches.

3. Reading Comprehension - The ability to read and effectively respond and/or take action to written instructions/material.

4. Observation Ability - The ability to recognize objects/people after they have undergone physical change.
5. Mathematical Reasoning - The ability to do foundational arithmetic and solve mathematical word problems.

6. Judgment and Decision Making - The ability to analyze incomplete information to make decisions.

7. Deductive Reasoning - The ability to make logical inferences from stated propositions.

8. Analytical Reasoning - The ability to understand, analyze, and evaluate arguments.

9. Report Writing - The ability to understand and properly use and spell words correctly.

10. Reading Maps and Diagrams - The ability to understand the linguistics of drawn materials.

11. Written Communication Skills - To what extent can the candidate effectively express ideas in writing?

The surveys were sent by email using Survey Monkey (SM) to the members of the Police Chief Associations of the states of Illinois, Indiana, Ohio, Nebraska, and Iowa, using list serves. ${ }^{28} \mathrm{~A}$ survey was also sent to members of the Caribbean Commissioners Association. The surveys were emailed to members of the six entities either by the association staff members or directly by the author using available list serves. In Table 1, the results of the two top alternatives of five levels of importance of alternatives Like rt Scale are illustrated in the table for the various state organizations and the Caribbean. The top two alternatives chosen for each of the 11items are Extremely Important and Very Important. Totals for the southern states and the Midwest are illustrated. The top two alternatives were chosen because the vast majority of the chiefs in the six entities chose them over the lower three alternatives. (The Like rt scale included five alternatives: extremely important, very important, but for this article only the data for the first two were recorded since the vast majority selected these two alternatives.) The following table represents a comparison of states' selections of alternative importance that corresponds with the 11 survey items.

Table I Most common preferences of respondents

\begin{tabular}{llllllllllllll}
\hline $\begin{array}{l}\text { Midwestern States } \\
\text { Respondents }\end{array}$ & \multicolumn{1}{l}{ IL IA NE } & OH IN SUm & MW \% & Carib SUM & Carib \% & Tot \\
Item & 76 & 40 & 20 & 28 & 18 & 182 & & 16 & & 198 \\
\hline I Memory & 64 & 33 & 16 & 23 & 15 & 151 & 83.4 & 14 & 87.5 & 165 \\
2 Judgment & 77 & 40 & 19 & 28 & 15 & 179 & 98.4 & 15 & 94 & 172 \\
3 Reading comprehension & 66 & 36 & 18 & 24 & 13 & 157 & 86.2 & 16 & 100 & 173 \\
4 Observation & 59 & 27 & 14 & 19 & 14 & 133 & 73 & 10 & 62.5 & 143 \\
5 Math reasoning & 15 & 6 & 6 & 2 & 3 & 32 & 17.6 & 4 & 25 & 36 \\
6 Decision-making & 75 & 39 & 17 & 28 & 18 & 177 & 97.3 & 13 & 81.3 & 190 \\
7 Deductive reasoning & 67 & 37 & 18 & 28 & 18 & 168 & 92.3 & 12 & 75 & 180 \\
8 Analytical reasoning & 69 & 35 & 18 & 23 & 17 & 162 & 89 & 12 & 75 & 174 \\
9 Report writing & 72 & 39 & 20 & 23 & 14 & 168 & 92.3 & 16 & 100 & 184 \\
I0 Map reading & 43 & 23 & 10 & 12 & 10 & 98 & 53.8 & 6 & 37.5 & 104 \\
II Writing skills & 72 & 37 & 20 & 26 & 17 & 172 & 94.5 & 14 & 87.5 & 186 \\
\hline
\end{tabular}




\section{Data analysis}

Asillustrated in Table 1, 182 Midwest police chiefs and 16 Caribbean commissioners (CCs) responded to the surveys. Survey Monkey distributed and collected the responses to the surveys sent to the chiefs' state association members in the states of Illinois, Indiana, Ohio, Nebraska, and Iowa surveys data, as well as the Caribbean Commissioners Association. The respondents included 198 respondents that included $16 \mathrm{CCs}, 76$ chiefs in Illinois, 40 in Iowa, 20 in Nebraska, 28 in Ohio, and 18in Indiana.

For Item 1, Memory is defined as the ability to recall the essence of previously studied material. This attribute is used frequently when making detailed reports after interviews have been conducted. Memory is related to Item 4, Observation Ability, in that an officer may recognize a person from a wanted flyer or missing person bulletin. In Table 1, of the 198 respondents to this attribute, 151 (83.4\%) of the state police chiefs chose the top two alternatives, extremely important or very important. Fourteen of the 16 Caribbean Commissioners (CCs) chose the top two alternatives. The distribution of the selections from the states included 64 from Illinois, 33 from Iowa, 16 from Nebraska, 23 from Ohio, 18 from Indiana (an overall percentage of 83.4 percent), and $14(87.5 \%)$ of the CCs.

Item 2, Judgment, refers to the ability to take appropriate action after considering alternative approaches (i.e., discretionary decision making). Discretion is used frequently by police officers in most jurisdictions while performing the job of policing. The misuse of discretion, however, during the performance of police duties can mean trouble for officers. Item 2 is similar to Item 6 in that they both deal with judgment, although Item 2 deals with discretionary decision making to take action (i.e., the analysis is based on alternatives allowed based on agency policy or law involving officer discretion, and Item 6 deals with the ability to make a decision based on analysis of limited information. As illustrated in Table 1, 189 of 198 respondents chose the highest level of importance for Judgment (almost 98.4\% of the chiefs and $94.5 \%$ of the $\mathrm{CCs}$ ).

Item 3, Reading Comprehension refers to reading and effectively responding and taking action on written instructions and materials. Electronic and hard copy directives are posted daily, and the standard operations and policy manual have to be understood. Adding their signatures or initials to the document generally acknowledges that officers have read and understand the manual. In service training on operating procedures and legal updates are provided by most departments. Officers cannot rely totally on their memory to cite laws, many of which are generated annually. In Table 1, 157police chiefs (about $86.2 \%$ ) and16 CCs $(100 \%)$ rated this attribute as extremely or very important. The choices for extremely and very important were consistent in percentages across the six entities.

Item 4, Observation Ability is being able to recognize objects and people after they have undergone physical change. Item 4 is similar to Item 1, Memory. Item 4involves the ability to recognize a face or vehicle from a printed or television notice. Other examples are a person wearing a disguise that may have a peculiar walk or a dispatcher who gives a description of a suspicious or wanted person and the officer then observes someone fitting the description. As illustrated in Table 1,133 chiefs and $10 \mathrm{CCs}$ out of 198 total respondents $(72.2 \%)$ rated this attribute as extremely or very important.
For Item 5, Mathematical Reasoning is the ability to do foundational arithmetic and solve mathematical word problems. The attribute is helpful with accident and crime scene reconstruction, firearm trajectories, and understanding the operation of the breathalyzer.

The attribute is also good for developing analytical or critical thinking skills. The Table 1 illustrates that Mathematical Reasoning has one of the lowest ratings overall in terms of level of importance. Only 32 police chiefs and four CCs $(18.1 \%)$ chose extremely or very important as their number one choice for this attribute.

Item 6, Judgment and Decision-Making, is the ability to analyze incomplete information to make decisions. This item is related to Item 2, Judgment. Item 2 deals with officer discretionary decision making on the basis of written policy, traffic law, and criminal law and procedure. Item 6 is making a decision based on analyzing limited information or situations not covered in written documents. It is similar to supplying a missing word to complete a sentence to fit into the context of a situation. The Judgment and Decision-Making attribute is based on experience in the environment. Item 2, Judgment, and Item 6, decision-making, had the overall highest Like rt Scale rating averages of all items, 190 of the 198 (95.9) responses. It is interesting to note that one police chief from Illinois, one from Iowa, and two from Nebraska rated this item as only important.

Item 7, Deductive Reasoning means making a presumption based on events, facts, and information available in a specific environment. The choices in the table show that 168 chiefs and 12 CCs (90.9\%) respondents, almost 91 percent, believed that Deductive Reasoning is either very important or extremely important. The next item in the table, Item 8 , is Analytical Reasoning, which is a systematic and logical evaluation through questioning the information available. The Analytical Reasoning attribute and was not selected as much as the two judgment attributes (Items 2 and 6), it is highly preferred characteristic of respondents. According to the data from the police chief and commissioners, $174(87.8 \%)$ chose the attribute as either extremely important or very important.

Item 9, Report Writing, is being able to understand and properly use and spell words correctly. Report writing is a very noticeable function in policing used frequently by officers who write many reports and summaries of events. Supervisors want comprehensible and error-free accounts which may end up in the prosecutor's office and the court. The ability to write well and accurately is necessary for all officers. Because of the observable nature of written reports and not knowing who may read them, a majority of the police chiefs believe it is imperative for the report does not embarrass the officer or the department with a poorly written report. The data in for this item indicate that $184(92.9 \%)$ of the respondents, a little under 93 percent, chose Report Writing as either extremely important or very important. This is an observable attribute used by all police officers, not just recruits.

Item 10, Reading Maps and Diagrams, is the ability to understand the semantics of maps and diagrams. It is as kill essential for understanding accident and crime scene schematics, and sometimes it is necessary for reading blueprints of buildings with hostage situations. The police chiefs' responses illustrate a mixed view of its importance. There was a division of those respondents choosing this item's importance as a desirable attribute. About half of the chiefs and a little more than a third of the commissioners indicated this skill was 
either extremely important or very important. The breakdown in the table shows total responses of 98 (53.8\%) of the chiefs and six (37.5\%) of the commissioner respondents chose extremely important or very important. These numbers seemed to indicate that this attribute did not seem as highly important as some of the others attributes.

Item 11 is Written Communication Skills, defined as the ability to put ideas in writing effectively. When writing reports, officers need to state precisely what they mean. Writing in a report needs to be comprehensible without police verbiage. It is best to use short declarative sentences. Sentences should be constructed carefully with clear statements so that there is no mistake about the accuracy of the matter. The report should be stated so well that anyone can read it, understand it, and react to it without the benefit of the officer's presence to explain. As indicated for Item 11 in the table, 172 of the police chief respondents $(94.5 \%)$ and 14 of the CCs $(87.5 \%)$ respondents (overall, this is 186 almost 94 percent), believe that Written Communication Skills are either very important or extremely important.

\section{Summary}

Based on the surveys, the responses of the police chiefs regarding the 11 desired attributes are consistent across the Midwest state and Caribbean surveys. ${ }^{27}$ The results are also consistent with the results of prior research in the southern states of Alabama, Florida, North and South Carolina, and Texas. ${ }^{2}$ Based on the literature review and the data recorded from the police chiefs in the surveys, there appears to be a need to overhaul the emphasis of selection assessments of police candidates who have the preferred skills and traits, that is, attributes. A Like rt Scale with five alternatives of importance levels served as the basis of the survey. The article included only the top two importance levels as indicated by the choices made by the chiefs and commissioners. The preferred attributes include the ability of officers to recall the essence of previously studied material; read and respond effectively, and follow written instructions and interpret material; choose appropriate action after considering alternative solutions; recognize objects and persons after they have undergone physical change; do foundational arithmetic and solve mathematical word problems; evaluate partial information to make decisions; make rational inferences from stated propositions; understand, analyze, and evaluate arguments; understand and properly use and spell words correctly; understand the semantics of drawn materials; and effectively express their ideas in writing. ${ }^{29-35}$

The review of the literature on research of selection illustrates the importance of selection. Furthermore, it is just as important for police agencies as training. We get an idea of the value placed on each attribute when looking at the levels of importance of attributes chosen by Midwest police chiefs and commissioners of the Caribbean. They believe these skills and traits do support a successful police career. The data indicate that the police chiefs in the Midwest states of Illinois, Iowa, Ohio, Indiana, and Nebraska. ${ }^{2}$ and commissioners of the Caribbean are fairly consistent with the levels of importance they place on the 11 attributes in the survey. Improvement efforts of selection and retention of officers in police agencies need to be substantial for several reasons. First, if recruits are selected with a history of poor behavior, there may be serious discipline problems later. Second, retention of qualified recruits as career officers who have the physical, mental, and emotional attributes to perform the job is important to the overall character of the agency. Third, retention is increased with supervisor contact, direction, training, and support. ${ }^{4}$

Determining an individual's potential to perform reliably and productively is extremely important for protecting the interests of communities. ${ }^{11}$ Selecting a recruit who will be successful in basic and in service training, and ultimately as a career police officer is dependent on the quality of selection methods. Selection methods in place should identify the attributes for successful performance of candidates. Since the police are the most visible of governmental employees, only the most competent should be identified and selected. The right selection assessment methods and training methods are imperative in securing an unwavering and dependable police force. ${ }^{36-38}$

Selection assessment methods should be developed based on criteria of agency needs. In addition to verifying information provided by candidate written applications, entry-level assessments are used to determine an applicant's suitability for policing. As previously mentioned, assessment methods can provide a diagnostic overview for both selection and training of candidates similar to determining success when applying to colleges, similar to colleges' use of SATscores. ${ }^{2}$

\section{Conclusion}

There is consensus for the need to train, but not for the attributes to look for in selection. There should also be consensus for selection assessment processes. This means selection assessment reform. Individuals charged with the development of the pre-employment screening procedures used to select police candidates in merit and non-merit systems must realize that improving selection methods must be an ongoing task. Public safety issues are in continuous flux; those involved in selection and training must be prepared to recognize and adapt to increasingly effective standards to meet new performance demands of policing. Research needs to continue toward improving assessment methods of selection. The future success of police officers who survive the rigorous selection process is dependent on recruits to have these distinctive skills and traits.

\section{Acknowledgments}

None.

\section{Conflicts of interest}

The author declares there are no conflicts of interest.

\section{References}

1. Frank J, Henson B, Reyns B, et al. Selection and hiring of quality police officers. Columbus: Ohio Office of Criminal Justice Services. 2008.

2. Martin RH, Gwynne JL, Hamilton S. A comparison of police chief essential police recruit attributes in Georgia, Alabama, and South Carolina. Law Enforcement Executive Forum. 2013;13(3):37-56.

3. Martin RH, Gwynne JL. An assessment of essential police candidate aptitudes and requirements in Alabama: Police training technologies. Law Enforcement Executive Forum. 2017;11(1):83-103.

4. Harris JJ. Picking and keeping law enforcement and corrections officers in Florida.

5. Martin RH. The significance of selected attributes police chiefs in Nebraska, Illinois, and Iowa believe necessary for recruit success in policing. Law Enforcement Executive Forum. 2016;16(1):68-89. 
6. Martin RH. Psychological assessment in police selection: Common and uncommon methods of personality evaluation. Law Enforcement Executive Forum. 2020

7. Dwyer WO, Prien EP, Bernard JL. Psychological screening of law enforcement officers: A case for job related- ness. Journal of Police Science and Administration. 1990;17(3):176-182.

8. Gaines LK, Worrall JL, Southerland MD, et al. Police administration 2nd ed. Boston: McGraw-Hill. 2003.

9. Gaines LK, Worrall JL. Police administration. $9^{\text {th }}$ ed. 2012

10. Martin RH. An alternative approach to preservice police basic training: Combining training and education learning outcomes. Community College Journal of Research and Practice. 2014;38(11):995-1007.

11. Martin RH, Hamilton S. Selecting the right recruit: Attributes preferred by Illinois and Iowa police chiefs. Law Enforcement Executive Forum. 2014;14(2):94-114.

12. Langham B. Millennials and improving recruitment in law enforcement. The Police Chief. 2017.

13. Cordner G, Cordner K. Human resource issues faced by small and large agencies. The Police Chief. 2014;91(3):14-15.

14. Scrivener E. Innovations in police recruitment hiring: Hiring in the spirit of service. Washington, DC: U.S. Department of Justice, Office of Community Oriented Policing Service, Community Policing Consortium. 2001.

15. Steel Claridge S. Selecting in recruits: Identifying traits and characteristics indicative of Florida highway patrol training academy success. The Police Chief. 2015;92(11):34-40.

16. Hunter F. A call for change. Command Publication: Illinois Association of Chiefs of Police. 1994:4:20-23.

17. Coulton GF, Field HS. Using assessment centers in selecting entry-leve police officers: Extravagance or justified expense? Public Personnel Management. 1995;24(2):223-254

18. Decicco DA. Police officer candidate assessment and selection. The FBI Law Enforcement Bulletin. 2000;69(12):1-6.

19. Cox SM, McCamey WP, Scaramella GL. Introduction to policing. 2nd ed. Thousand Oaks, CA: Sage. 2014.

20. U. S. Government Office of Personnel Management. Assessment selection: Other selection methods. 2019.

21. Peak KJ. Policing America: Challenges and best practices. Upper Saddle River, NJ: Prentice Hall. 2009

22. Peak KJ, Glensor RW. Community policing and problem solving: Strategies and practices. 6th ed. 2012
23. Arthur W Jr, Day EA, McNelly TL, et al. A meta-analysis of the criterion-related validity of assessment center dimensions. Personnel Psychology. 2003;56(1):125-153.

24. Dayan K, Ronen K, Fox S. Entry- level police candidate assessment center: An efficient tool or a hammer to kill a fly? Personnel Psychology. 2002;55(4):827-849.

25. Walker S, Katz CM. The police in America: An introduction. 8th ed. New York: McGraw-Hill. 2009

26. More HW, Miller LS. Effective police supervision. 5th ed. New York: Lexis-Nexis, Anderson. 2007

27. Martin RH. Preferred Caribbean commissioners recruit attributes for successful police training and careers. Law Enforcement Executive Forum. 2018;18(1):13-29.

28. Martin RH. Police chiefs' comparisons of ratings of preferred attributes of police recruits for successful careers: Surveys of Indiana, North Carolina, and Ohio police chief association members. Law Enforcement Executive Forum. 2011;19(4):38-50.

29. Allen RJ. Effective supervision in the police service-England. London: McGraw- Hill. 1978.

30. Benton SR, Martin RH. Police crisis intervention: The need to train Law Enforcement Executive Forum. 2012;13(1):110-127.

31. Commission on Accreditation for Law Enforcement Agencies (CALEA). Standards for law enforcement agencies: The standards manual of the law enforcement agency accreditation program. Fairfax, VA: CALEA. 2006.

32. Czarnecki F. The role of pre-employment screenings: Medical screening of police applicants. The Police Chief. 2014;91(3):46-51.

33. International Association of Chiefs of Police (IACP). Improving 21st century policing through priority research: The IACP's national law enforcement research agenda. 2008.

34. Martin RH. Wellness: A matter of health. In: W Doerner, ML Dantzker, editors. Police organization and management: Contemporary issues. Boston: Butterworth-Heinemann. 2000.

35. Miller LS, More HW, Braswell MC. Effective police supervision. $8^{\text {th }}$ ed. NY: Rutledge. 2017.

36. Roland J, Greene RL, Hampton G, et al. Building a better work- force through the use of pre-employment psychological evaluations. The Police Chief. 2014;91(3):48-49.

37. Ross DL. Emerging trends in police failure to train liability. Policing. An Inter- national Journal of Police Strategies \& Management. 2000;23(2):169-193.

38. Thibault EA, Lynch LM, McBride RB. Proactive police management. 6th ed. Upper Saddle River, NJ: Pearson/Prentice Hall. 2004. 